\title{
Comparative Lipid Isolation Protocols from Rhizophora mucronata L. of Dharmadam Estuary and Lipid Profiling in the Context of a Non Mangrove Mangifera indica \\ Meera SP, Anusha S and Anu A*
}

Department of Biotechnology and Microbiology, Kannur University, Thalassery Campus, Palayad P.O., Kannur- 670661, Kerala, India

\begin{abstract}
The effects of salt stress on lipid composition of mature mangrove plant, Rhizophora mucronata grown in estuarine water (0.391 M Chloride ion concentration and 3020 ppm salinity) and yield of total lipids from two original protocols and four modified protocols were evaluated. It is the first approach for isolation of mangrove lipids, in which propanol treatment was used, which resulted in two fold increase in lipid yield. Rhizophora mucronata lipid composition is categorized into seven prominent classes: Polar lipids, Unknown, Sterols, Free fatty acids, Tri-terpenoids, Wax esters and Stero esters. Comparative study of mangrove lipid profile (Rhizophora mucronata control and Rhizophora mucronata mature) with that of a salt sensitive tree Mangifera indica showed that in Rhizophora mucronata plants grown in high saline conditions, the concentration of sterol esters, wax esters and sterols get decreased and tri-terpenoids, free fatty acids, unknown lipids and polar lipids get increased.
\end{abstract}

Keywords: Mangroves; Halophyte; Rhizophora mucronata; Lipid; Salinity; Stress

\section{Abbreviations}

IR: Infra-Red Spectroscopy; NMR: Nuclear Magnetic Resonance Spectroscopy; MS: Mass Spectrometry; OD: Optical Density; HPTLC: High Performance Thin Layer Chromatography; PVPP: Poly-vinyl Poly-pyrrolidone; UV: Ultra-Violet; ppm: Parts Per Million

\section{Introduction}

Mangroves are prominent halophytic inhabitants of intertidal zone found in tropical and subtropical climates thriving under varying degrees of salinity, ranging from fresh to levels greater than that of seawater [1]. Salinity imposes quite a few stumbling blocks in overall plant cellular metabolic processes which includes water deficit caused by salt induced osmotic stress and the toxic effects due to ion excess. These salt-tolerant plants (mangroves) have advanced mechanisms to cope with the harmful after effects of salinity stress. Despite the fact that stress tolerance mechanisms of plants materialized to be composite and divergent, various lines of mechanisms have been proposed for their salt tolerance properties: osmotic potential across the cell membrane is balanced by the accumulation of low molecular weight osmolytes, such as glycine betaine, sugar alcohols and proline [2-4] and stress induced damages get repaired by the production of stress-inducible proteins and other biomolecules, of which vivid physiological function is yet to become apparent [5-9].

The plant-cell membrane itself is a basic and potential barrier to a number of external factors in addition to these metabolic shifts to overcome environmental difficulties. Here comes the paramount part of lipids in cell membranes for adapting plants to environmental stresses. Salt stress prompted alterations in plant lipid bilayer composition and membrane permeability due to salt stress were reported earlier by various authors [10-12]. Such modifications of the lipid bilayer result in transmuted membrane fluidity and $\mathrm{H}^{+}$- ATPase activity, influencing the passive influx of potentially toxic ions such as $\mathrm{Na}^{+}$and $\mathrm{Cl}^{-}[10,13]$. Plasma membrane permeability is an instinctive property of the lipid composition and the lipid-protein interaction [13]. In spite of this, few studies have focused on the lipid composition of mangrove plants. It is important to study the salt tolerance mechanism of individual genera or species because mangrove trees have evolved their own peculiar mechanism to adapt to specific environment and shows complexity and discrepancy between species. Although mangroves are comprised of a great diversity of plants, the genus Rhizophora is one of the prevalent representatives of the plant groups in India [14]. To get a vivid picture, lipid composition of mangrove plant Rhizophora mucronata is compared with that of a woody glycophyte Mangifera indica. The present study also recounts different modified protocols for the isolation of total lipids from the leaves of mangrove plant Rhizophora mucronata. Lipid composition of the leaves of Rhizophora mucronata is examined for the first time. From the study, it was found that the Tri-terpenoids formed the predominant lipid class in Rhizophora mucronata, suggesting that these lipids may have a prominent role in salt tolerance.

\section{Materials and Methods}

\section{Taxonomic identification of Rhizophora mucronata}

Anatomical features like leaves with elongated (mucronated) tips, axillary clusters of flowers on twigs, cream colored calyx with four sepals and four white, hairy petals and viviparous seeds were observed for the taxonomic identification.

Determination of chloride ion concentration of estuarine water by titration with silver nitrate (Boyle's method).

Chloride ion concentration of estuarine water near the area from where the mature leaf samples of Rhizophora mucronata were collected was estimated manually by titration with silver nitrate [15].

*Corresponding author: Anu Augustine, Department of Biotechnology and Microbiology, Kannur University, Thalassery Campus, Palayad P.O., Kannur670661, Kerala, India, Tel: +91 9447151040; Fax: 0490-2345317; E-mail: anuaugus@rediffmail.com

Received: May 13, 2015; Accepted: August 22, 2016; Published August 26, 2016

Citation: Meera SP, Anusha S, Anu A (2016) Comparative Lipid Isolation Protocols from Rhizophora mucronata L of Dharmadam Estuary and Lipid Profiling in the Context of a Non Mangrove Mangifera indica. Biochem Anal Biochem 5: 286 doi:10.4172/2161-1009.1000286

Copyright: (C) 2016 Meera SP, et al. This is an open-access article distributed unde the terms of the Creative Commons Attribution License, which permits unrestricted use, distribution, and reproduction in any medium, provided the original author and source are credited. 
Citation: Meera SP, Anusha S, Anu A (2016) Comparative Lipid Isolation Protocols from Rhizophora mucronata L. of Dharmadam Estuary and Lipid Profiling in the Context of a Non Mangrove Mangifera indica. Biochem Anal Biochem 5: 286. doi:10.4172/2161-1009.1000286

Page 2 of 6

\section{Checking accuracy with a positive control}

A clean burette was filled with $0.1 \mathrm{M}$ silver nitrate solution $\left(\mathrm{AgNO}_{3}\right)$ and titrated against $10.0 \mathrm{ml}$ of the stock $0.1 \mathrm{M} \mathrm{NaCl}(\mathrm{aq})$ solution in a conical flask containing potassium chromate indicator. $\mathrm{AgNO}_{3}$ was added slowly to the contents of the conical flask, while continually swirling the conical flask till the first permanent red-orange color appeared. The new volume of solution in the burette was recorded. Experiment was repeated thrice.

\section{Estimation of unknown sample}

Unknown estuarine water $(10 \mathrm{ml})$ was titrated with $0.1 \mathrm{M} \mathrm{AgNO}_{3}$ (aq) solution, using potassium chromate as indicator. Experiment was repeated thrice.

\section{Determination of salinity of estuarine water by electrical con- ductivity measurement}

Total salinity of the estuarine water near the area from where the mature leaf samples of Rhizophora mucronata were collected, was measured using Conductivity meter 306 (SYSTRONICS, Soil Testing Laboratory, Kerala Agriculture Department, Kannur). The reading was taken three times at 10 minute intervals.

\section{Sample collection for lipid isolation}

Rhizophora mucronata propagules were collected and planted in pots. Plants were watered several months with normal tap water and used as control. Leaves of Rhizophora mucronata trees were collected from the mangrove ecosystem of Melur riverside (Dharmadam estuary) and used as the salt stressed sample. Leaves of Mangifera indica collected from Elayavoor (Remote village away from sea shore) were used as the salt sensitive sample. All the leaf samples were ground to fine powder using liquid nitrogen and stored at $-80^{\circ} \mathrm{C}$ for lipid isolation.

\section{Lipid Extraction with Different Protocols for Yield Comparison}

Two original protocols and four modified protocols were tried for lipid extraction from the mature leaf samples of Rhizophora mucronata grown in estuarine water of salinity $3020 \mathrm{ppm}$ and the yields were compared

\section{Protocol 1(Bligh and Dyer method)}

One gram of fresh mass was fixed by heating in boiling water (10 $\mathrm{ml}$ ) for $2 \mathrm{~min}$ to inactivate lipophilic enzymes. Fixed material was homogenized with $20 \mathrm{ml}$ methanol/chloroform (1:1 v/v) and then, re suspended in $10 \mathrm{ml}$ of boiling water containing $0.88 \% \mathrm{NaCl}$ for fixation. The mixture was shaken vigorously, let to rest for $5 \mathrm{~min}$ and centrifuged at $500 \times \mathrm{g}$ for $10 \mathrm{~min}$. The supernatant was centrifuged again at 3,000 $\times \mathrm{g}$ for $15 \mathrm{~min}$ and a two phase mixture was obtained. The lipid phase, soluble in chloroform was separated and the water soluble phase was once again suspended in $10 \mathrm{ml}$ chloroform for extraction of residual lipids. Extracts were stored at $-20^{\circ} \mathrm{C}$

\section{Protocol 2 (Folch method)}

One gram of leaves ground in liquid nitrogen was extracted with $25 \times$ volume of chloroform/methanol (2:1, by volume; CM21). The cell-wall debris that was insoluble to CM21 was removed by filtration through no. 2 filter paper (Whatman), and the filtrate was centrifuged at $14,000 \mathrm{rpm}$ for $10 \mathrm{~min} .0 .88 \%$ potassium chloride was added, shaken vigorously and kept for centrifugation at $500 \times \mathrm{g}$ for $10 \mathrm{~min}$. Lower phase was removed and treated with activated charcoal for chlorophyll removal [16].

\section{Protocol 3: Modification with propanol treatment followed by Folch method}

One gram leaves ground in liquid nitrogen was extracted with 10 volumes of propan-2-ol [17] and centrifuged at $500 \times \mathrm{g}$ for $10 \mathrm{~min}$. The solid phase was then homogenized with $25 \times$ volume of chloroform/ methanol (2:1, by volume; CM21). The cell-wall debris that was insoluble to CM21 was removed by filtration through no. 2 filter paper (Whatman), and the filtrate was centrifuged at 14,000 rpm for $10 \mathrm{~min}$. $0.88 \%$ potassium chloride was added, shaken vigorously and kept for centrifugation at $500 \times \mathrm{g}$ for $10 \mathrm{~min}$. Lower phase was removed and treated with activated charcoal for chlorophyll removal.

\section{Protocol 4: Modification with Polyvinyl polypyrrolidone (PVPP) treatment followed by Folch method}

One gram of leaves ground in liquid nitrogen was extracted with $25 \times$ volume of chloroform/methanol (2:1, by volume; CM21) and PVPP. The cell-wall debris that was insoluble to CM21 was removed by filtration through no. 2 filter paper (Whatman), and the filtrate was centrifuged at $14,000 \mathrm{rpm}$ for $10 \mathrm{~min} .0 .88 \%$ potassium chloride was added, shaken vigorously and kept for centrifugation at $500 \times \mathrm{g}$ for 10 min. Lower phase was removed and treated with activated charcoal for chlorophyll removal.

\section{Protocol 5: Modification with Sodium acetate treatment fol- lowed by Folch method}

One gram of leaves ground in liquid nitrogen was extracted with 25 $\times$ volume of chloroform/methanol (2:1, by volume; CM21) and Sodium acetate. The cell-wall debris that was insoluble to CM21 was removed by filtration through no. 2 filter paper (Whatman), and the filtrate was centrifuged at $14,000 \mathrm{rpm}$ for $10 \mathrm{~min} .0 .88 \%$ potassium chloride was added, shaken vigorously and kept for centrifugation at $500 \times \mathrm{g}$ for 10 min. Lower phase was removed and treated with activated charcoal for chlorophyll removal.

\section{Protocol 6: A combination of three modifications (Propanol, PVPP and Sodium acetate) followed by Folch method}

One gram leaves ground in liquid nitrogen was extracted with 10 volumes of propan-2-ol and centrifuged at $500 \times \mathrm{g}$ for $10 \mathrm{~min}$. The solid phase was then homogenized with $25 \times$ volume of chloroform/ methanol (2:1, by volume; CM21), PVPP and Sodium acetate. The cell-wall debris that was insoluble to CM21 was removed by filtration through no. 2 filter paper (Whatman), and the filtrate was centrifuged at $14,000 \mathrm{rpm}$ for $10 \mathrm{~min} .0 .88 \%$ potassium chloride was added, shaken vigorously and kept for centrifugation at $500 \times \mathrm{g}$ for $10 \mathrm{~min}$. Lower phase was removed and treated with activated charcoal for chlorophyll removal.

\section{Estimation of total lipids}

For the estimation of total lipids, $100 \mathrm{mg}$ per $100 \mathrm{ml}$ of a commercial vegetable oil (Olive oil) in chloroform was used as standard. Aliquots of lipid extracts and standards in test tubes were placed in a water bath at $100^{\circ} \mathrm{C}$ to evaporate the solvent. $0.2 \mathrm{ml}$ of sulfuric acid was added and heated for $10 \mathrm{~min}$ at $100^{\circ} \mathrm{C}$. All the samples were made up to $5 \mathrm{ml}$ with vanillin reagent and mixed well. Samples were cooled and kept for approximately $5 \mathrm{~min}$ till a reddish color developed. OD was measured at $625 \mathrm{~nm}$ within 30 minutes [18]. 
Citation: Meera SP, Anusha S, Anu A (2016) Comparative Lipid Isolation Protocols from Rhizophora mucronata L. of Dharmadam Estuary and Lipid Profiling in the Context of a Non Mangrove Mangifera indica. Biochem Anal Biochem 5: 286. doi:10.4172/2161-1009.1000286

Page 3 of 6

\section{Isolation of total lipids to elucidate their response with salin- ity change}

Folch method was followed for isolating lipids from the leaves of Rhizophora mucronata control (watered with tap water), Rhizophora mucronata mature (grown in estuarine water of salinity $3020 \mathrm{ppm}$ ) and Mangifera indica (Salt sensitive sample).

\section{Analysis of lipid composition}

For the analysis of total lipid composition, aliquots of lipid extract were applied to $10 \times 10 \mathrm{~cm}$ high performance thin layer chromatography (HPTLC) plates (Pre coated silica gel 60 F254, Merck). The plates were first developed to their full length with hexane and successively with benzene, and finally to their half-length with hexane/ether/acetic acid (70: 30: 1, by vol.). After drying in a stream of air, the plates were immersed in phosphoric acid $33 \%$ acetic acid/sulfuric acid $/ 0.5 \%$ copper sulfate (5: 5: 0.5: 90 , by vol.) for $40 \mathrm{sec}$ and heated at $130^{\circ} \mathrm{C}$ for $12 \mathrm{~min}$. The chromatograms were documented by TLC visualizer (CAMAG) under $366 \mathrm{~nm}$ UV light.

\section{Discussion}

Mangroves are good reservoir for isolation of biomolecules including lipids involved in salt stress tolerance $[19,20]$. The problem of isolating lipids from mangrove leaves seems to be magnified due to release of high concentration of polyphenolics and metabolites after disruption of the cells, which are embedded in viscous polysaccharides. This may be the reason why lipids were not isolated by Bligh and Dyer method. Furthermore, samples from different species and tissues show differences in their composition [21,22]. The lipids from plant sources and photosynthetic tissues especially, are liable to undergo extensive enzyme-catalyzed degradation when extracted with chloroformmethanol mixture. The problem is best overcome by means of a preliminary extraction with propanol. Introduction of propanol treatment doubled the lipid yield than the routine Folch extraction. The insoluble PVPP binds to and removes phenolic compounds and sodium acetate eliminates polysaccharides. So these were introduced in the protocol to see whether the phenolic compounds and polysaccharides exhibit any inhibitory effect in the isolation of total lipids from the leaves of Rhizophora mucronata, which is rich in phenolic compounds. The yield of unsaturated lipids reduced with PVPP treatment. PVPP acts by complexing polyphenols through the mechanism of hydrogen bonding as its chemical structure resembles that of amino acid proline. The active hydroxyl groups in tri-terpenoids and others sterols may cross interact with PVPP to account for a reduced lipid yield [23]. The yield of unsaturated lipids reduced in the presence of sodium acetate also. The combination of propanol, PVPP and Sodium acetate gave a better yield of unsaturated lipids. The chemical nature and structural differences between individual lipid classes correspond to fluctuations in yield a various modifications in the isolation protocol.

To conclude, total lipids from mangrove can be properly isolated with propanol treatment following Folch method to result in a better yield. The major class of lipids present in Rhizophora mucronata plants is Tri-terpenoids and the lipid composition of this specific mangrove species is yet to be reported. Separation of an unknown lipid class was noticed upon HPTLC, which need further analysis like IR, NMR and MS to elucidate its chemical structure in future but the concentration was insufficient to go for structural elucidation. Comparing the changes of lipid composition with salinity it was clear that Rhizophora mucronata plants grown under high saline conditions showed lowered levels of Sterol esters, Wax esters and sterols and higher levels of tri-terpenoids, free fatty acids, unknown lipids and polar lipids. Mangroves thus are a reservoir of lipid types and there is a need to focus on the lipid composition, the salt induced alterations of lipids in mangroves and the unique genes involved in lipid production of mangroves.

\section{Results}

\section{Sample collection and identification}

The trees of Rhizophora mucronata are average sized with stilt arch roots and prop roots. Their leaves are oval shape and wide and have brown spots on the underside surface. The tip and base of the leaves are broad and thorny on the underside. Comparing these features, it was confirmed and taxonomically identified as Rhizophora mucronata. Rhizophora mucronata being a facultative halophyte can adapt to environmental salinity and modulate the biomolecule production with respect to the presence or absence of salinity. Rhizophora plants watered several months with normal tap water were used as control (Figure 1). Leaves collected from mangrove area of Melur (Dharmadam estuary) were used as the mature sample (Figure 2). Leaves of Mangifera indica collected from Elayavoor were used as the salt sensitive control.

\section{Determination of chloride ion concentration of estuarine wa-} ter by titration with silver nitrate (Boyle's method)

The titre value of estuarine water near the area from where the mature leaf samples of Rhizophora mucronata were collected was

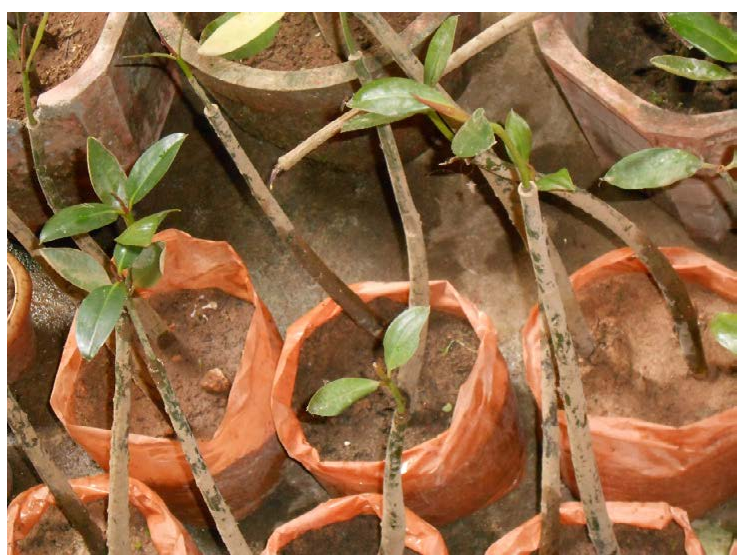

Figure 1: Control plants grown in pots.

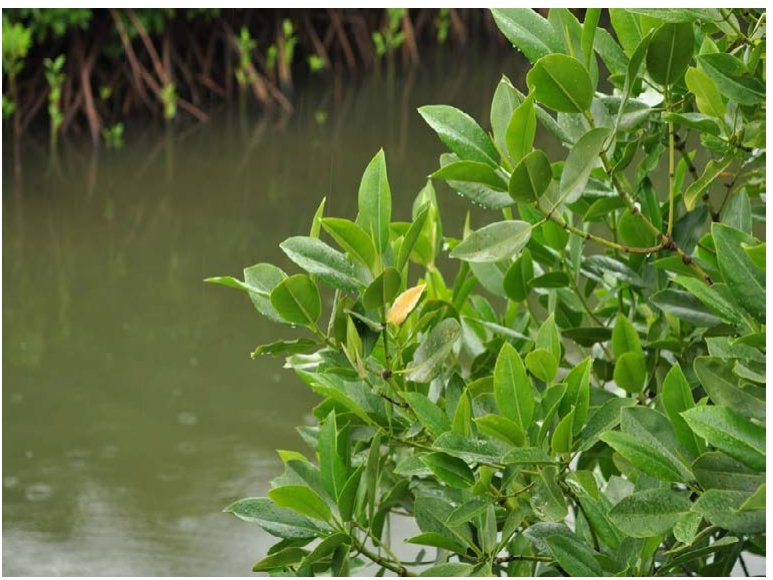

Figure 2: Rhizophora mucronata plant (from Dharmadam estuary). 
Citation: Meera SP, Anusha S, Anu A (2016) Comparative Lipid Isolation Protocols from Rhizophora mucronata L. of Dharmadam Estuary and Lipid Profiling in the Context of a Non Mangrove Mangifera indica. Biochem Anal Biochem 5: 286. doi:10.4172/2161-1009.1000286

obtained as $39.1 \pm 0.058$ and the chloride ion concentration was calculated from the titre value as $0.391 \mathrm{M}(13.862 \mathrm{ppm})$. Molarity of chloride ions ranges from $0.0 \mathrm{M}$ in fresh water to $0.5 \mathrm{M}$ in the open ocean. The value $0.391 \mathrm{M}$ clearly corresponds to moderate chloride ion concentration between fresh water and sea water that is termed estuarine water or brackish water.

\section{Determination of salinity of estuarine water by electrical con- ductivity measurement}

Total salinity of the estuarine water near the area from where the mature leaf samples of Rhizophora mucronata had been collected was $3020 \mathrm{ppm}$ which represents the electrical conductivity of all the ions in the water sample. Salt concentration in slightly saline water is around 1,000 to $3,000 \mathrm{ppm}(0.1-0.3 \%)$, in moderately saline water 3,000 to $10,000 \mathrm{ppm}(0.3-1 \%)$ and in highly saline water 10,000 to $35,000 \mathrm{ppm}(1-3.5 \%)$. Sea water has a salinity of roughly 35,000 ppm, equivalent to 35 grams of salt per one liter (or kilogram) of water. Here the value $3020 \mathrm{ppm}$ lies in the moderately saline water range and represent estuarine or brackish water.

Total lipid extraction, estimation of unsaturation and analysis of lipid composition by high performance thin layer chromatography

Two original protocols and four modified protocols were tried for lipid extraction from the leaf samples and the yields were compared by estimating the total lipid following vanillin reaction (Figure 3 and Table 1). The vanillin reaction requires a carbon - carbon double bond. Concentrated sulfuric acid reacts with unsaturated lipids in the initial step to form a carbonium ion. Phosphoric acid reacts with vanillin to produce a phosphate ester with a resulting increase in the reactivity of the carbonyl group. The carbonium ion reacts with the carbonyl group of phosphor-vanillin to form a colored compound which is read at $624 \mathrm{~nm}$. After estimating the lipid content, all the isolated lipids were analyzed for their composition by HPTLC.

It was observed that the lipid isolation was not proper with Protocol 1 (Bligh and Dyer method).

Successful lipid isolation was obtained with the second protocol (Folch method) and the concentration of unsaturated lipids in the total lipid extract was found to be $0.636 \mu \mathrm{g} / \mu \mathrm{l}$. To compare the change in yields with different modifications, isolation was repeated with other protocols. Introduction of propanol treatment in the routine Folch method doubled the lipid yield and the concentration was found to be $1.308 \mu \mathrm{g} / \mu \mathrm{l}$. The yield of unsaturated lipid gets reduced with PVPP treatment and the concentration obtained was $0.289 \mu \mathrm{g} /$ $\mu$ l. Introduction of Sodium acetate in the protocol also reduced the yield of unsaturated lipids to a concentration value $0.399 \mu \mathrm{g} / \mu \mathrm{l}$. The combination of propanol, PVPP and Sodium acetate gave a better yield of unsaturated lipids and the final concentration was $0.592 \mu \mathrm{g} / \mu \mathrm{l}$.

A total of 7 major classes of lipids were seen upon HPTLC separation of lipid extracts of Rhizophora mucronata (Figures 4 and 5). Comparison with the standards reported earlier led to the grouping as polar lipids (The lipid remaining at the original position, and essentially denotes the phospholipid and galactolipid fractions), unknown, sterols, free fatty acids, tri-terpenoids, wax esters and sterol esters. HPTLC analysis of all the samples clearly indicated that the tri-terpenoids are the major class of lipids in Rhizophora mucronata. Separation of sterol esters and wax esters were found to be comparatively higher in Protocol 2, 4 and 5. The comparative study also revealed the lack of correlation between the concentration of unsaturated lipid and proper separation

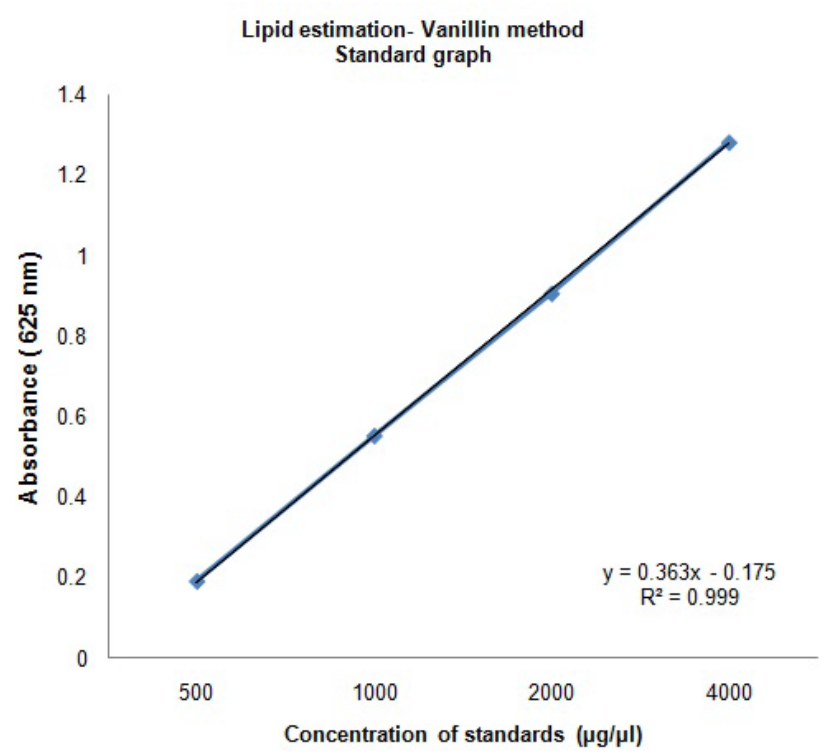

Figure 3: Standard graph plotted with concentration of olive oil on $X$ axis and Optical density at $625 \mathrm{~nm}$ on Y-axis. Concentrations of test solutions were calculated from the linear equation of the standard graph.

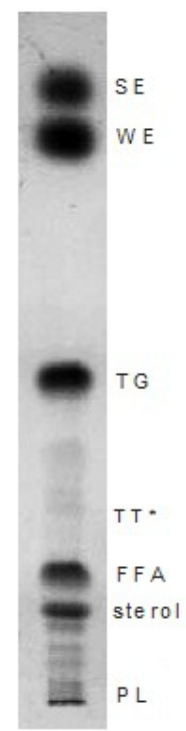

Figure 4: Banding pattern of Lipid standards upon HPTLC using the same solvent system from the literature (Oku et al. 2003). Cholesteryl oleate (sterol esters, SE), Stearyl oleate (wax esters, WE), Triolein (triacylglycerols,TG), Triterpenoids (just above FFA, structurally confirmed by Oku et al., TT*), Oleic acid (free fatty acids, FFA), Cholesterol (sterols), PL (polar lipid).

\begin{tabular}{|l|l|l|}
\hline Sample & OD mean value & Concentration $(\boldsymbol{\mu g} / \mu \mathrm{l})$ \\
\hline Protocol 2, Mature mangrove & $0.406 \pm 0.023$ & 0.636 \\
\hline Protocol 3, Mature mangrove & $0.65 \pm 0.006$ & 1.308 \\
\hline Protocol 4, Mature mangrove & $0.28 \pm 0.01$ & 0.289 \\
\hline Protocol 5, Mature mangrove & $0.32 \pm 0.02$ & 0.399 \\
\hline Protocol 6, Mature mangrove & $0.39 \pm 0.01$ & 0.592 \\
\hline
\end{tabular}

Table 1: Concentration of unsaturated lipids present in the lipid extracts from different protocols. 
Citation: Meera SP, Anusha S, Anu A (2016) Comparative Lipid Isolation Protocols from Rhizophora mucronata L. of Dharmadam Estuary and Lipid Profiling in the Context of a Non Mangrove Mangifera indica. Biochem Anal Biochem 5: 286. doi:10.4172/2161-1009.1000286

on HPTLC (Table 2) which may be due to the interaction of individual lipid classes with the components of each protocol.

Isolated lipids from the leaves of Rhizophora mucronata control (watered with tap water), Rhizophora mucronata mature (Salt tolerant, growing in estuarine water of salinity $3020 \mathrm{ppm}$ ) and Mangifera indica (Salt sensitive sample) showed a marked difference in lipid composition upon HPTLC analysis (Figure 6). Rhizophora Control and Mangifera samples were found to be having Sterol esters and wax esters whereas Rhizophora mature samples did not give any corresponding bands. Other lipid classes like tri-terpenoids, free fatty acids, polar lipids and the unknown lipid were evidently higher in Rhizophora mature sample compared to others. While comparing sterols, the band obtained was slightly less in Rhizophora mature sample than the other ones. It was clear from the observations that with the increase in salinity stress,

\begin{tabular}{|l|l|l|}
\hline $\begin{array}{l}\text { Order from highest to } \\
\text { lowest }\end{array}$ & $\begin{array}{l}\text { Concentration of } \\
\text { Unsaturated lipids }\end{array}$ & $\begin{array}{l}\text { Proper separation on } \\
\text { HPTLC }\end{array}$ \\
\hline 1 & Protocol 3(Propanol) & $\begin{array}{l}\text { Protocol 5(Sodium } \\
\text { acetate) }\end{array}$ \\
\hline 2 & Protocol 2 (Folch original) & Protocol 4 (PVPP) \\
\hline 3 & $\begin{array}{l}\text { Protocol 6 (Propanol + } \\
\text { PVPP + Sodium acetate) }\end{array}$ & $\begin{array}{l}\text { Protocol 2 (Folch } \\
\text { original) }\end{array}$ \\
\hline 4 & Protocol 5(Sodium acetate) & Protocol 3(Propanol) \\
\hline 5 & Protocol 4 (PVPP) & $\begin{array}{l}\text { Protocol 6 (Propanol + } \\
\text { PVPP + Sodium acetate) }\end{array}$ \\
\hline
\end{tabular}

Table 2: Comparison of total yield of lipids and presence of individual lipids from each protocol.

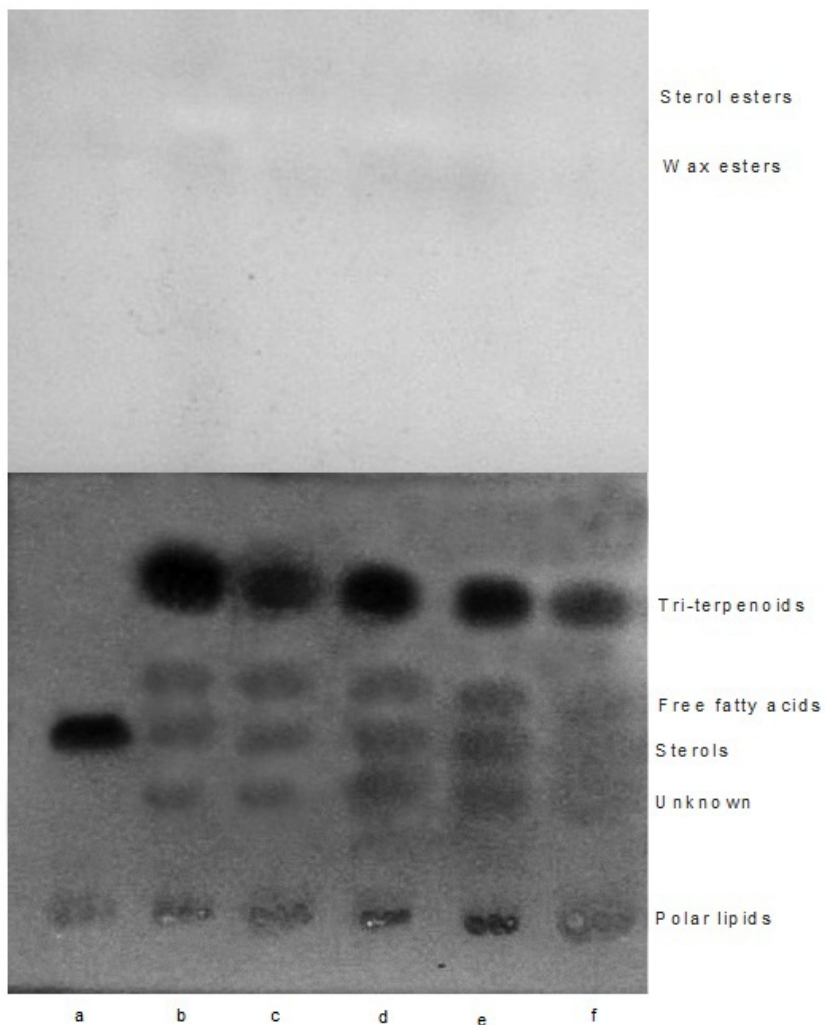

Figure 5: HPTLC chromatograms of the total lipid from mature mangrove leaves. a: Cholesterol Standard, b: Protocol 2 (Folch method original), c: Protocol 3 (Propanol), d: Protocol 4 (PVPP), e: Protocol 5 (Sodium acetate), f: Protocol 6 (Propanol + PVPP + Sodium acetate).

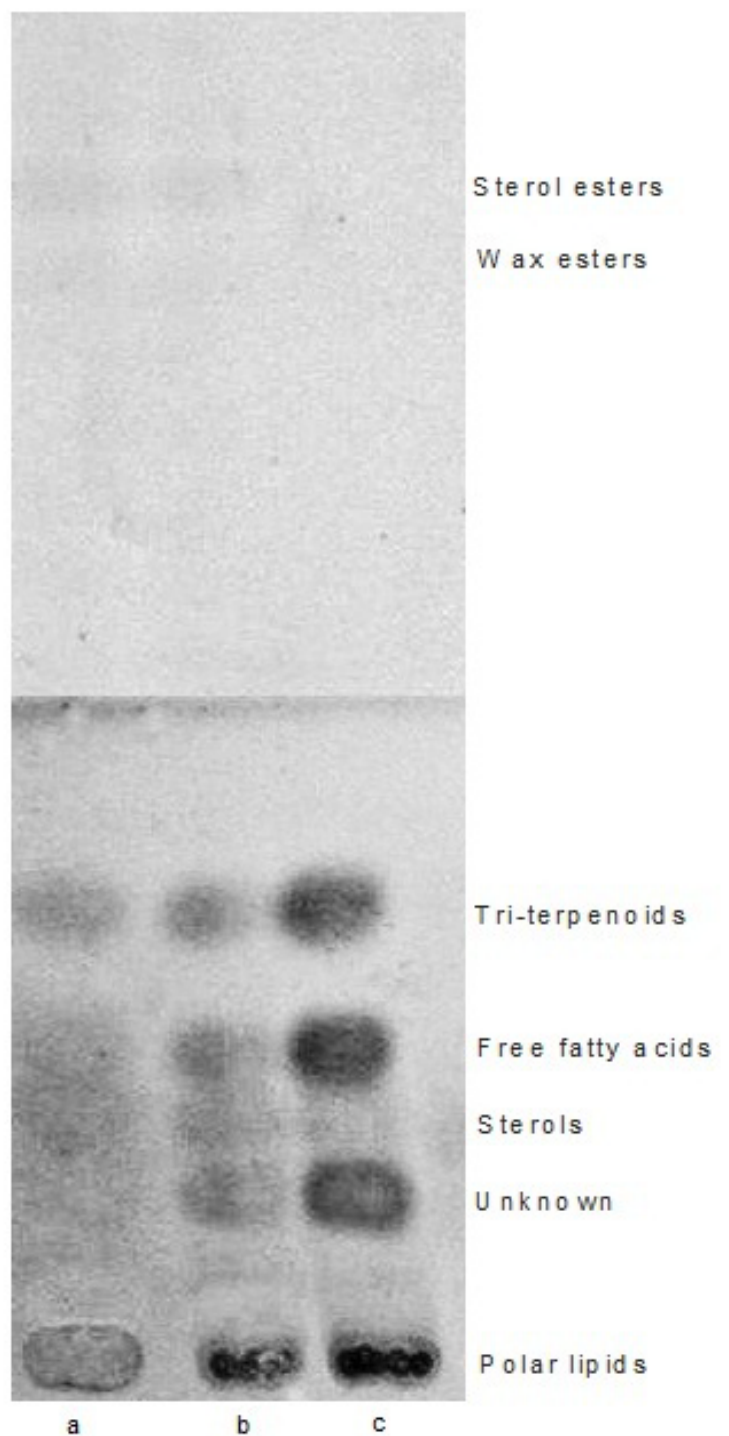

Figure 6: HPTLC chromatograms of the total lipid from a: Mangifera indica (Salt sensitive sample), b: Rhizophora mucronata control (watered with tap water) and c: Rhizophora mucronata mature (Salt tolerant, growing in estuarine water of salinity 3020 ppm leaves.

sterol esters, wax esters and sterols get decreased and tri-terpenoids, free fatty acids, unknown lipids and polar lipids get increased.

\section{Acknowledgments}

The financial support received from Kerala State Council for Science Technology and Environment (KSCSTE) and University Grants Commission (UGC) is gratefully acknowledged.

\section{References}

1. Tomlinson PB (1986) The botany of mangroves. Cambridge University Press, London

2. Popp M (1984) Chemical composition of Australian mangroves. II. Low molecular weight carbohydrates. Z Pflanzenphysiol 113: 411-412.

3. Fan TW, Colmer TD, Lane AN, Higashi RM (1993) Determination of metabolites by $1 \mathrm{H}-\mathrm{NMR}$ and GC: Analysis for organic osmolytes in crude tissue extracts. Anal Biochem 214: 260-271.

4. Bohnert HJ, Nelson DE, Jensen RG (1995) Adaptations to environmental stresses. Plant Cell 7: 1099-1111. 
Citation: Meera SP, Anusha S, Anu A (2016) Comparative Lipid Isolation Protocols from Rhizophora mucronata L. of Dharmadam Estuary and Lipid Profiling in the Context of a Non Mangrove Mangifera indica. Biochem Anal Biochem 5: 286. doi:10.4172/2161-1009.1000286

5. Singh NK, Brancker CA, Hasegawa PM, Handa AK, Buckel S, et al. (1987) Characterization of osmotin: a thaumatin-like protein associated with osmotic adaptation in plant cells. Plant Physiol 85: 529-536.

6. King GJ, Turner V, Hussey C, Wurtele E, Mark Lee S (1988) Isolation and characterization of a tomato cDNA clone which codes for a salt induced protein. Plant Mol Biol 10: 401-412.

7. Hurkman WJ, Tao HP, Tanaka CK (1991) Germin-like polypeptides increase in barley roots during salt stress. Plant Physiol 97: 366-374.

8. Moons A, Bauw G, Prinsen E, Montagu MV, Straeten D (1995) Molecular and physiological responses to abscisic acid and salts in roots of salt-sensitive and salt-tolerant indica rice varieties. Plant Physiol 107: 177-186.

9. Sugihara K, Hanagata N, Dubinsky Z, Baba S, Karube I (2000) Molecular characterization of cDNA encoding oxygen evolving enhancer 45protein 1 increased by salt treatment in the mangrove Bruguiera gymnorrhiza. Plant Cell Physiol 41: 1279-1285

10. Kerkeb L, Donaire JP, Venema K, Rodriguez-Rosales MP (2001) Tolerance to $\mathrm{NaCl}$ induces changes in plasma membrane lipid composition, fluidity and $\mathrm{H}^{+}$ ATPase activity of tomato calli. Physiol Plantarum 113: 217-224.

11. Elkahoui S, Smaoui A, Zarrouk M, Ghrir R, Limam F (2004) Saltinduced lipid changes in Catharanthus roseus cultured cell suspensions. Phytochemistry 65 : 1911-1917.

12. Lope'z-Pe'rez L, Martinez-Ballesta MC, Maurel C, Carvajal M (2009) Changes in plasma membrane lipids, aquaporins and proton pump of broccoli roots, as an adaptation mechanism to salinity. Phytochemistry 70: 492-500.

13. Mansour MMF, Salama KHA (2004) Cellular basis of salinity tolerance in plants. Environ Exp Bot 52: 113-122.
14. Duke NC, Ying Lo EY, Sun M (2002) Global distribution and genetic discontinuities of mangroves emerging patterns in the evolution of Rhizophora. Trees 16: 65-79.

15. Boyle RW (1968) Geochemistry of silver and its deposit notes on geochemical prospecting for the element. Geological Survey of Canada: 160.

16. Folch JLM, Lees M, Sloane-Stanley GH (1957) A simple method for the isolation and purification of total lipids from animal tissues. J Biol Chem 226: 497-509.

17. Kates M, Eberhardt FM (1957) Isolation and fractionation of leaf phosphatides. Can. J. Bot 35: 895-905.

18. Van Handel E (1985) Rapid determination of total lipids in mosquitoes. J Am Mosq Control Assoc 1: 302-304

19. Meera SP, Anusha S, Anu A (2013) Functional screening and genetic engineering of mangrove salt responsive genes: A Review. Annals of Plant Sciences 2: $535-542$

20. Anusha S, Meera SP, Anu A (2014) A review on transporters in salt tolerant mangroves. Trees 28: 957-960

21. Hibino T, Meng YL, Kawamitsu Y, Uehara N, Matsuda N, et al (2001) Molecular cloning and functional characterization of two kinds of betaine-aldehyde dehydrogenase in betaine-accumulating mangrove Avicennia marina (Forsk.) Vierh. Plant Mol Biol 45: 353-363

22. Wu J, Xiao Q, Xu J, Li M, Pan J, et al. (2008) Natural products from true mangrove flora: source, chemistry and bioactivities. Natural Product Reports 25: 955-981.

23. Rehmanji M, Gopal C, Mola A (2002) A novel stabilization of beer with polyclar brewbrite. MBAA TQ 39: 24-28 